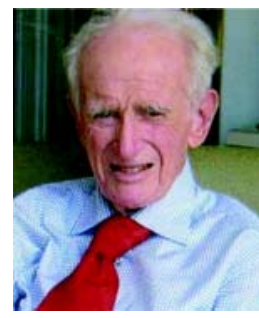

\title{
George Rowan Nicks AO, OBE, MD(Honoris Causa), FRCS, FRACS
}

ROWAN NICKS was born in New Zealand on 24

February 1913. He studied medicine at the University of Otago in Dunedin and, on graduation in 1937, worked as an intern at Auckland City Hospital. After his internship, he moved to the United Kingdom to further his surgical studies, working as a demonstrator in anatomy at Middlesex Hospital, London.

Rowan served as a Surgeon Lieutenant in the Royal Navy during the Second World War. In 1945, he was appointed Officer of the Order of the British Empire and became a Fellow of the Royal College of Surgeons.

After the war, he turned his attention to cardiothoracic surgery, and worked at Royal Brompton Hospital, London. In 1947, he returned to New Zealand to pioneer cardiothoracic surgery at Greenlane Hospital in Auckland.

In 1956, Rowan was appointed Staff Specialist in Cardiothoracic Surgery at Royal Prince Alfred Hospital in Sydney. He was involved in the beginning of open-heart surgery in New South Wales in 1957 and played a leading role in the design and development of the first automatic cardiac pacemaker.
After the death of his wife Mary in 1969, Rowan travelled widely, visiting hospitals in Africa and India in particular. This was the beginning of his second career as a significant philanthropist.

After his official retirement in 1973, Rowan continued to travel and work in hospitals in East Africa, India and Malaysia, as well as in remote Aboriginal communities in Australia. Rowan established a series of scholarships and fellowships for young surgeons from Africa, India, Asia, the United Kingdom and Ireland, and the Western Pacific region. In 2005, he established the Rowan Nicks Russell Drysdale Fellowship in Australian Indigenous Health and Welfare.

Throughout his life, Rowan had a sustaining love of nature and gardening. In his later years, he developed his interest in chamber music, symphony and opera. Rowan died on 26 May 2011, and is survived by his extended family in Australia and New Zealand.

John Masterton, Brian Morgan doi: 10.5694/mjall.10759 